\title{
1. Introduction: finance, risk, and statistics
}

Starting in the 1950s, a small group of economists began using the methods of statistics to study financial markets. Their path-breaking work revolutionized the study of investing and created a new field of financial economics with the simple idea that risk can be measured with statistical methods. Every revolution has antecedents, however, and this book will study the forerunners of modern financial economics.

Financial economics has not been considered an important topic in the history of economic thought, with a few exceptions (Crockett 1980; Markowitz 1999; Miller 1999; Poitras 2000; and Rubinstein 2003). In this book, I am going to focus on a group of economists who used the methods of probability theory and statistics to analyze financial markets in the period before 1950. These economic thinkers were explorers, seeking places for the paths to be started. Along the way, they found resistance to their ideas among holders of traditional views of finance and economics. Those skeptics regarding the application of statistics to finance will also be part of the story told in this book.

\section{MODERN FINANCIAL ECONOMICS}

Before the development of modern financial economics, investors in financial securities followed a number of strategies in making their decisions. Technical analysis and its companion approach the Dow Theory, which dates back to the 1890s (both will be described more fully in Chapter 6), use charts of stock prices in order to find trends investors could use to buy on an upswing and sell before a downswing (technical analysis) or looks for signs of long-term bull or bear markets (Dow Theory). Value analysis, usually attributed to Benjamin Graham and David Dodd (see Chapter 7) and their classic book, Security Analysis (Graham and Dodd 1934), offers techniques to locate stocks that were undervalued by looking for companies whose stock price did not reflect the growth potential or true value of the company.

As part of modern financial economics, however, probability theory and statistical methods have countered the firm-specific methods of technical 
analysis and value analysis. The statistical methods of modern financial economics assume that changes in stock prices are random, that is to say that past prices do not predict future prices. One way of establishing the randomness of changes in stock prices is to look at them through the methods of statistics and demonstrate that they behave in the same way as any other random variable. Studies have successfully accomplished this exercise. Economists, however, dislike having to rely on statistical evidence that does not relate to a theory or hypothesis. They prefer to offer theoretical explanations for why statistical results are valid.

In financial economics, the efficient markets theory provides a powerful explanation for the randomness of changes in stock prices. To understand how this theory works, we can start with the economists' model of perfect competition. In that model, a competitive market is defined as having a large number of buyers and sellers with no buyer or seller being large enough to influence the market, no barriers to entry, and perfect information about market conditions. Holding everything else constant, the circumstances of perfect competition will produce an equilibrium price that satisfies both buyers and sellers and that price will be sustained as long as nothing else in the market changes.

This efficient markets theory starts with the idea that financial markets, especially stock markets, come very close to the definition of perfect competition. Stock market transactions involve many buyers and sellers every day, anyone can buy or sell in those markets with minimal barriers, and no one can dominate the millions of daily transactions. Regarding information, the efficient markets theory holds that since investors all have access to the same information about securities, they reach the same conclusions about which stocks to buy or sell. As a result, a stock's price will tend toward an equilibrium that reflects a fair value for the business in terms of current estimates of its future earning power. When investors discover new information that changes those estimates, they will take actions that cause stock prices to change. With a constant flood of information, the equilibrium price of a stock will be changing continuously.

More important, the efficient markets theory holds that since investors and analysts always look for investment opportunities, they will eventually find every stock that is producing above-average gains due to poor estimates of its future earnings. They will buy those stocks and force their prices to levels consistent with their future earning. Consequently, when above-average gains do exist, they cannot last for very long. It is not easy to make abnormal gains in the stock market using investment methods based on public information. Competition among investors will eliminate any short-term gains.

The efficient markets theory implies that stock prices follow a random pattern to the extent that the information investors receive about stocks is 
random. If the stock market sets a fair price for stocks, as the efficient markets theory asserts, those prices will change only when investors decide that the stock prices are not fair. In part, investors will change their minds on the basis of new information that causes them to believe that a stock's price is too high or too low. If the information that influences investors is random, its impact on investors and their decisions will also be random.

The conclusions its advocates draw from the efficient markets theory are that technical analysis will not work and that value analysis cannot produce consistent gains. The only way to earn a higher return is to take on more systemic risk, that is, there is a trade-off between risk and return. The challenge for investors, then, is to determine how much risk they are taking and decide whether their potential returns are worth that risk. One of the most powerful tools of financial economics is its use of probability theory and statistical methods to analyze risk.

The efficient markets theory takes on a number of forms, depending on how efficient an analyst believes markets really are. Financial economists now agree that perfectly efficient financial markets do not exist. In the main, however, financial economists have reached a point where they believe that even if they are not perfectly efficient, financial markets are sufficiently efficient for the efficient markets theory to be useful in using diversification to reduce risk (Putnam and Zimmer 1987, pp. 26-30). Consequently, the efficient markets theory remains an integral part of modern financial economics, although its dominance has waned since its general acceptance in the 1970s and its validity is much debated (Findlay and Williams 2000/2001, p. 11).

In recent years, moreover, behavioral economists have added to the debate over whether financial markets are efficient (Lo and MacKinley 1999 and Shiller 2002, pp. 1-12). At the heart of the model of perfect competition and its corollary the efficient markets theory is the assumption that buyers and sellers are rational in their behavior. In the last decade, however, researchers in behavioral finance, by applying psychology to investor behavior, have found that investors do not always behave rationally. For example, the 'fear of regret' may make investors avoid selling stocks that have lost value to avoid acknowledging the pain caused by making a poor investment. Investors also place too much emphasis on recent trends in financial markets and extend them into the future even when they go against what statistical analysis shows to be probable. These and other psychological behaviors may lead investors to make inefficient investment decisions. (Hirshleifer 2001, pp. 1533-95 and Nofsinger 2001). Feedback models of behavioral finance indicate that investors can spur each other on and create 'bubbles' of irrationally rising stock prices (Shiller 2002, pp. 14-22) that contradict the notion that financial markets are efficient. 
The conclusions drawn from behavioral finance, however, do not provide a strong counter to the idea that asset prices are a random variable. Inefficient investment decisions may produce random movements in asset prices. Moreover, it does not take a perfectly efficient market to make the point that investors need to consider the risks they are running when they buy financial assets. The discipline required to apply statistical methods can serve as an antidote to irrational behavior.

This book will explore the intellectual history of the efficient markets theory, the belief that stock price changes are random, and the study of investment risk by economists. It will focus on statistical approaches to risk analysis and will pay special attention to those that used Bayesian statistics. It will also point out earlier versions of behavioral finance that disputed the validity of statistical approaches to finance and will look at early versions of technical and value analysis. Before those approaches can be appreciated, I will first explain what investment risk is and how modern financial economists analyze it.

\section{INVESTMENT RISK}

All of life carries the risk that the future will not turn out the way we plan. In thinking about risk, economists make a distinction between risk and uncertainty. The difference between risk and uncertainty to economists is that risk refers to cases where the future is unknown but the probability of events in the future can be measured with statistical methods, while uncertainty exists when the probability of future events cannot be measured. From this perspective, investment risk is the probability that we will not earn as much as we expect on our investments. It includes the chance that as a result we will not have enough income to fulfill our plans and obligations.

Investment risk exists because the future is unknowable. Each purchase or sale of an investment security is a bet on where its price will be in the future. Since bets are forecasts on the future, there is a risk that the future will turn out differently. An investor can lose the bet that he or she made in buying the security. That is why all investment has risk. Modern financial economics uses probability theory and statistical methods to analyze risk, to give odds in terms of probability estimates on the bet an investor makes by purchasing an asset. To the extent that we can assign a probability to the risk of investments with these methods, it becomes possible to manage that risk.

There are two types of investment risk. Firm-specific risk is the risk associated with the price of an individual security. At any time, the price of an individual stock, for example, will depend on the quality of the company's management, conditions in the company's industry, and the company's 
product development. All of these can have an affect on the company's current and future profits. It is current and future profits that impact on the stock's price. Information that has a bearing on a company's expected future profits will change its stock prices.

Market risk is the risk associated with fluctuations in the stock market. All stocks move up and down when the stock market changes. Market risk can be affected by general economic conditions, such as changes in the interest rate or the growth of gross domestic product (GDP). It is also influenced by investor sentiment and confidence, which in turn are affected by a variety of events ranging from war to political elections.

Firm-specific risk can be reduced through the use of a diversified portfolio. In theory, a well-diversified portfolio will include assets whose prices move inversely or are not related at all, so that if one stock declines its losses can be offset by increases in another stock. There are few assets that have these traits, however. In practice, a diversified portfolio should avoid stocks whose movements are too closely parallel. Studies have shown that as few as 20 diversified stocks can eliminate firm-specific risk, leaving an investor to face market risk. To reduce market risk, an investor can include assets in his or her portfolio that are not affected by general changes in the stock market. Government or corporate bonds have the potential to offset the effect general changes in stock prices will have on a portfolio.

Whenever an investor buys an individual stock, he or she is looking for a gain from growth in the price of the stock and from dividend income. The price of the stock will fluctuate, however, as a result of either firm-specific risk or market risk. It is not always easy to tell which of the two types of risk will cause a stock price to fluctuate. Modern financial economics has developed ways to measure the total risk of a stock, however. It uses many of the same methods to assess the risk of a portfolio.

This book will document innovative efforts among economists to develop an understanding of investment risk. Modern economic theories of investment risk rely on statistics. While not all of the economic thinkers to be studied in this book used statistics, statistics came to be a tool in finance during the period under study here, 1900 to 1950 . While the economists studied in this book came from the United States, financial economists now attribute the starting point of their field to the work of a French mathematical statistician Louis Bachelier, who wrote in the early years of the twentieth century.

\section{RISK, PROBABILITY, AND STATISTICS}

Before looking at Bachelier's signal contribution to financial economics, it is necessary to draw a clear distinction between probability theory and statistics. 
In general, probability theory provides a way to describe the outcomes that one can anticipate in looking at events in the world. In economics it is used as a supplement to economic theory in the sense that theories make predictions about the outcomes of human activities and probability theory gives the theorist a way to think about the likelihood of the prediction being verified. Statistics are the data that represent the anticipated outcomes, and statistical methods are then used to make inferences about whether the data verify the anticipated outcome.

The economists surveyed in this book used both probability theory and statistics in their studies. We will see, for example, that Irving Fisher used a specific theory of probability that influenced his theory of investment decision making. He also pioneered in many statistical studies, but I found none that related to his theory of investment behavior. Bachelier, to whose work we now turn, did both, but his contribution is in the area of probability theory.

Thus we see that in his now classic article, 'Theory of Speculation,' Louis Bachelier used mathematics to investigate the probability of making investment gains through forecasting price changes in securities, in his case an early form of an option, a probability he believed was 'impossible to predict in a mathematical manner.' His mathematics showed a glimmer of hope for analyzing the probability distribution of changes in the prices of financial assets and the expected gains or losses that resulted from them, however. He wrote, 'Evidently the probability is governed by the Gaussian law, already famous in the calculus of probabilities' (Bachelier 1900 in Cootner 1965, pp. 27-31).

With mathematical rigor, given his assumptions, Bachelier established the idea that changes in the prices of financial assets were random and could be described as following a normal distribution. This meant that movements of those prices could not be predicted with precision. Nevertheless, they moved in a way that could be analyzed using statistics. Bachelier's article was based on his doctoral dissertation written at the University of Paris in 1900 under the direction of the great mathematician, Henri Poincare.

Bachelier had a key insight into what made security prices unpredictable. Every sale of a security is also a purchase. This implied that 'at the same instant buyers believe in a price increase and sellers believe in a price decrease.' Given this divided opinion among investors, any slight change in information or investor outlook can change the price in either direction. An increase is just as likely as a decrease, and no one could predict which would take place (Bernstein 1992, pp. 18-22).

Bachelier's work was not much appreciated in his day. Poincare did not grade his dissertation as earning the highest honors. He felt that its topic was too removed from what statisticians and probability theorists should be studying. Peter Bernstein, in his history of investment methods, tells us that 
Bachelier's dissertation and a small book he published on it in 1914 vanished from academic discussion until L.J. Savage, a statistician at the University of Chicago, accidentally found the book at a library in the 1950s. Savage was impressed and spread the word about Bachelier to economist friends. One of them, Paul Samuelson, was even more impressed, and made Bachelier well known throughout the economics profession (Bernstein 1992, pp. 22-3).

Bachelier's rise to prominence is a classic case of his finally being in the right place at the right time. By the 1950s, financial economics was coming under the influence of economists, who advocated the use of probability theory and statistical methods as a way of thinking about finance and investments, spurred on by the development of modern portfolio theory by Harry Markowitz. Markowitz's article, 'Portfolio Selection' (Markowitz 1952), is acknowledged to have been the key publication in the development of modern financial economics. Mark Rubinstein calls its publication 'the moment of birth of modern financial economics' (Rubinstein 2002, p. 1041).

In the article, Markowitz described how investors might choose a portfolio using a rule based on the mean and variance of expected returns (Markowitz 1952 , p. 77). In using this rule, he pointed out a problem inherent to it, 'Diversification cannot eliminate all variance.' To address it, he then stated the principle underlying his own approach to diversification as follows:

The portfolio with maximum expected return is not necessarily the one with minimum variance. There is a rate at which the investor can gain expected return by taking on variance, or reducing variance by giving up expected return (Markowitz 1952, p. 79).

This statement of the trade-off between risk and return in a portfolio seems very simple, but it greatly increased our understanding of finance.

In presenting his approach, Markowitz understood that the variance of a portfolio would be a complicated summing of the covariances of each security with other individual securities times the weights of those securities in the portfolio (Markowitz 1952, pp. 80-1). The entire operation rested on Markowitz considering the returns on the securities as random variables. He explained in a footnote that he assumed that an investor acted with probability beliefs concerning the future prospects of securities. That meant that an investor could tell which of two events was most likely to happen or if they were equally likely and be consistent in those probability beliefs regarding important decisions that had been given serious consideration. The investor must also act based on those probability beliefs, 'even though they be in part subjective' (Markowitz 1952, p. 81).

The mean-variance approach meant that an investor should select from a set of efficient portfolios, the ones with a minimum variance for a given expected return or a maximum return for a given variance (Markowitz 1952, p. 82). 
A portfolio was inefficient if another portfolio with the same return and a lower variance could be found or if another portfolio with a higher return and the same variance could be found. After an investor discarded the inefficient portfolios, he or she would be left with the set of efficient portfolios for which higher returns came only with higher variance.

The analysis of how to use the mean-variance approach that Markowitz presented was entirely theoretical. He did review some practical implications of the theory, however. First, the mean-variance approach allowed for the possibility of the discounted future value method; it was possible that the set of efficient portfolios included a portfolio of one stock with a maximum return and minimum variance, but that was not likely. Second, the mean-variance approach required investors to diversify by purchasing stocks in a variety of industries and by looking for securities that did not have high covariances. Investors needed to find securities that reacted differently to changes in the economy and to each other. Third, if an investor invested money in two portfolios with equal variance, then the variance of the combined portfolio would generally be less than the variance of either of the individual portfolios (Markowitz 1952, p. 89).

Could investors take steps consistent with these implications? Markowitz explained how they could. The key was in finding reasonable values for the mean and variance of a portfolio. To do so, he advised procedures that combined statistics with judgment. Statistics would provide estimates of the mean and variance of returns, and judgment would adjust some of those means and variances to account for factors whose probability could not be calculated readily. With this revised set of means and variances, investors should be able to find the right portfolio to suit their needs.

In the Markowitz paradigm, the return of an asset is expressed as a mean of past returns while the risk of an asset becomes the variance of those returns. A well-diversified portfolio can eliminate firm-specific risk, leaving the investor subject only to market risk. Markowitz later observed 'that standard deviation (rather than variance) is the intuitively meaningful measure of dispersion' and thus of risk (Markowitz 1999, p. 6). Regardless, modern financial economists refer to the approach he pioneered as the mean-variance approach.

The development of this approach set off a revolution in financial economics that is still taking place. In addition to Markowitz's portfolio theory, the option pricing model derived by Fischer Black and Myron Scholes and the capital asset pricing model developed by William Sharpe used meanvariance analysis in their technique (Miller 1999). To focus on the pricing of options through arbitrage methods, Black and Scholes utilized the stock price, the option's strike price and expiration date, the current risk-free interest rate, and the standard deviation (volatility) of the stock's return to place a price on an option. Their approach assumes that the stock underlying the option pays 
no dividends during the life of the option and that the risk-free interest rate is constant over the life of the option. Sharpe showed how the market prices of individual securities fluctuated in relation to their asset class by using beta to measure the volatility of the security relative to the asset class. Beta is a statistical estimate of how changes in the security correlate with changes in the asset class. The higher the beta, the riskier the stock and the higher the return above the risk free rate an investor would expect to earn on the security.

While these advances in quantitative finance are important, they are also evidence of a beguiling issue raised by Stephen Stigler in his collection of essays on the history of statistics:

Much of the material presented in modern courses on statistical methods for social sciences is superficially similar to texts available by 1830 , and yet the adoption of these methods for the different purposes of the social scientists was so glacially slow that it amounted to a reinvention.

Stigler dates the beginnings of the use of statistics in the social sciences to the late nineteenth century (Stigler 1999, p. 3). In the same vein, we might ask: did financial economics take another half-century to see the value of statistics for analyzing stock prices?

The answer I will give in this book is that economists and financial analysts did use statistics to analyze asset prices for the half-century before Markowitz wrote his article. In making this point, I do not intend to downplay Markowitz's accomplishment. Many great contributions to the history of science seem deceptively simple once we know about them. Rather, it is the goal of this study to document the efforts of a small number of economists who had discovered what Markowitz made conventional: stock market price changes can be treated as a random variable to be analyzed with statistical tools.

To say that changes in stock prices are a random variable is to say that any pattern in stock prices would mean nothing more than would a long series of heads in a coin flip. To be sure, stock prices may trend upward due to a firm's accumulation of retained earnings, but there will also be fluctuations around that trend. Because practitioners of modern financial economics believe that stock prices are random, they measure the risk of a security under the assumption that changes in its price approximate a normal distribution. The normal distribution is the familiar bell-shaped curve with a mean and a standard deviation indicative of a pattern of equal variation around the mean. For normal curves, 68 percent of those values are within one standard deviation of the mean and 95 percent are within two.

As applied to investments, the statistical approach computes the return an investor can expect as the mean or average of returns for a given period. The risk of the security is measured by the standard deviation of that return. The 
economists to be studied in this book took diverse attitudes toward this statistical approach to investment risk. Many of them adhered to it and believed that stock prices could be analyzed using the methods of statistics under the assumption that stocks followed the Gaussian law as Bachelier had shown. However, with the possible exception of Irving Fisher and John Maynard Keynes, as I will explore in Chapters 3 and 7, they did not use his article as a source for their ideas. Had they read it, they would have found its mathematics difficult. Regardless, they devised approaches to stock market analysis that employed the basic approach of using the mean of returns of a stock as its expected return and the standard deviations of those returns as its risk.

There is another aspect of their work that I will explore. One of the interesting discoveries this study has produced is that early practitioners in statistical finance followed a Bayesian approach, although they did not call themselves Bayesians. As just noted, Markowitz was aware that investors had to act on subjective probability beliefs (Markowitz 1952, p. 81) and subjective probability beliefs are at the heart of Bayesian statistics. The forerunners of modern financial economics also recognized the subjective nature of investors' decisions, and some of their approaches to statistics mirrored the view of probability set forth by Thomas Bayes. To appreciate these approaches, I will give a brief history and overview of Bayesian economic statistics as a part of the development of economic statistics in Chapter 2. For now, let us look at how current financial economists use the Bayesian approach.

\section{BAYESIAN APPROACHES TO FINANCE}

The usual application of probability theory and statistics to finance, as just described, contains an assumption of some importance: the relationships underlying the structure of the economy and the structure of financial markets are constant. Economic history tells us that this assumption is heroic, to say the least. The structure of the economy and of financial markets constantly changes. The innovation of the internet, with its application in the 'new economy' and in online stock trading, is just one recent example of how quickly these structures can change.

To take these structural changes into account, in recent years, financial economists have begun using another important statistical approach, Bayesian statistics (Norland and Stabile 2000). As I will describe in the next chapter, Bayesian statistics has long existed as alternate to the traditional type of statistics. Simply put, the Bayesian approach treats the mean and variance of a distribution as random variables while the traditional approach takes them as estimates of the true mean and variance of the distribution. The overriding 
philosophy of Bayesians, to use the words of Arnold Zellner, a leading advocate of Bayesian methods, is 'that a major objective of science is learning from our data and experience' (Zellner 1997, p. 42). This philosophy fits well with work in financial markets.

In contrast to the Bayesian approach, the classical or frequentist version of statistics is not well suited for applications in finance. It assumes that the parameters that govern the state of nature are fixed and the function of statistics is to produce estimates of them. In finance, however, practitioners recognize that the important relationships such as return and risk are not only volatile but evolve over time. Bayesian statistics allows analysts to add new information to their data and see how their previous results about parameters change over time. They can measure changes in risk and return by incorporating new information into their models.

A central point of Bayesian statistics is that probability is subjective. For reasons that will be explored throughout this book, Bayesians hold that the probability of any event taking place will depend on the assumptions made about the conditions under which the event will take place. Where the event to be studied is a social phenomenon, human judgment about the conditions surrounding the event becomes especially crucial in determining the probability of the event. Given that humans do not have identical judgments about social conditions, they will differ regarding the likelihood of an event's taking place. Here again, I will note Markowitz's recognition that investors acted on the basis of subjective probability beliefs (Markowitz 1952, p. 81).

The idea that probability is subjective fits well with financial markets and the data they provide. If investors did not have different expectations about the likelihood of their getting a return from an investment, there would be no need for a stock market. The stock market is where investors take the risk that their expectations are correct. As investors keep track of what happens to their stock, they add new information to their estimate of the likelihood that the stock will give them the return they expect. Bayes's approach, with its emphasis on the value of new information, was a natural for stock market research.

Because traditional statistics, as applied to finance, assumes that there is a true mean and variance that the sample of returns approximates based on past data, its methods also carry an assumption that the future will be just like the past. Financial markets, however, are especially dynamic. Not only do prices change all the time, the underlying structure of financial markets and the economy they mirror also change all the time. Financial markets, too, are quick to adjust to changes in their own structure.

By assuming that the parameters of a distribution, the mean and standard deviation, are randomly changing over time, the Bayesian approach gives a dynamic estimation of volatility in financial markets that is based on all 
information available, including new information. When new data become available, the Bayesian approach is to revise the probability distribution of the parameters. This approach then gives a forward-looking estimate of the expected return of an asset or portfolio as well as a revised estimate of its standard deviation.

Given the applicability of Bayesian methods to finance, we might wonder why the pioneers of financial economics in the 1950s did not use them. In part it may have been that the methods of Bayesian statistics needed the development of high-speed computers to be useful. But there is more to it than that. The probability theory related to Bayes could have been used to develop theoretical models that were at least verifiable. The gist of that philosophy is simple: probability is subjective. Its use as a measure of risk is also subjective. I have mentioned Markowitz's recognition that investment decisions may use subjective probability beliefs several times to make a point that his recognition did not lead him to Bayesian methods in 1952, although he made use of them later (see Chapter 9). Why Bayesian probability theory did not figure more strongly in the works of the pioneers of financial economics in the 1950s is another issue this book will consider.

\section{OVERVIEW OF THE BOOK}

This book will trace out the development of a variety of approaches to finance, with an emphasis on statistical methods, for the period 1900 to 1950. This is the period before Markowitz presented his path-breaking approach, and this book is partly a search for antecedents of the statistical approach to finance. Following this introductory Chapter 1, Chapter 2 will provide a brief survey of the history of statistics with an emphasis on economic statistics and the Bayesian perspective; it will argue that early in the twentieth century prominent economists viewed Bayesian statistics favorably, but by the 1930s and 1940s interest in Bayes among economists waned. Chapter 3 will describe Irving Fisher as an early advocate of statistical measures of risk and establish his credentials as a significant forerunner of financial economics with a Bayesian philosophy. Chapter 4 will explore Thorstein Veblen's theories of credit risk and behavioral finance and how they influenced two of his prominent followers, Wesley Mitchell and Herbert Davenport, to study financial markets in a way that anticipated modern financial economics. Chapter 5 will investigate how Frank Knight advanced the definition of risk and how Edgar Lawrence Smith, Irving Fisher, and other economic analysts viewed diversification and risk during the stock market boom and bust of the 1920s. In Chapter 6, the aftermath of the stock market collapse of 1929-33 will be considered by looking at statistical studies of the effectiveness of stock 
price forecasting and technical analysis, especially those undertaken by Alfred Cowles. Value analysis, the topic of Chapter 7, will be evaluated by analyzing the approaches of John Maynard Keynes, John Burr Williams, and Benjamin Graham and David Dodd to show why they downplayed statistical methods and how those methods could have added to their approaches. Chapter 8 will set the stage for the modern financial economics by describing the state of investment analysis in the decade of World War II. A concluding Chapter 9 will consider the relations between the ideas of the forerunners of modern financial economics and those of the innovators of it with special attention to a revival of Bayesian statistics in financial economics.

In working through this material, I will be presenting evidence in support of a major theme and two minor ones. First, the major theme: starting around 1900, a group of economists in the United States did believe that changes in stock prices could be treated as a random variable to be analyzed with statistical methods and used early versions of the efficient markets theory to justify their belief. Second, and less important, among the methods they used we can find elements of Bayesian probability theory; and third, their use of probability theory and statistical tools found opposition, especially among economists who should be included among the forerunners of behavioral finance.

\section{CONCLUSION}

The statistical methods of modern financial economics offer investors an alternative method for analyzing their decisions. We can see how innovative they are by considering that the traditional forms of investment analysis, technical analysis and value analysis, offer investors little insight into how much risk they are taking. The most important step in making money through investments in financial markets is to minimize the risk of losing that money.

This book will not give direct advice on how to minimize that risk. It is a study of how the forerunners of modern financial economics believed that risk could be analyzed. Its readers are warned that my presentation of the ideas of those forerunners is more descriptive than analytical. My goal has been to present what they said with little criticism of how valuable their ideas were for making money. In keeping with that goal, readers will gain knowledge of what these economists had to say and can then form their own opinions about the effectiveness of the methods they developed.

Readers should also keep in mind one other basic lesson. The rigorous statistical methods of modern financial economics were never intended to provide precise rules for investment decisions. Their purpose is to offer guidance to investors to give them the discipline to keep them from making 
bad decisions. Statistical tools cannot replace human judgment, the ultimate tool for making investment decisions. No matter how well statistics can measure chance, the decision to take the chance remains a human one based on subjective estimates of that chance. In this sense, all investors are Bayesians, or should be. 